\title{
CALDERÓN, PERSONAJE DRAMÁTICO ROMÁNTICO: DON PEDRO CALDERÓN (1867) DE PATRICIO DE LA ESCOSURA
}

\author{
Carlos Mata Induráin \\ Universidad de Navarra, GRISO \\ Edificio Biblioteca \\ 31009 Pamplona. España \\ cmatain@unav.es
}

En este trabajo pretendo mostrar cómo queda reflejada la figura de Pedro Calderón de la Barca en la comedia de Patricio de la Escosura Don Pedro Calderón (escrita en 1866, estrenada y publicada en 1867). En ella vamos a encontrar al genial dramaturgo convertido en ser de ficción, en un personaje dramático romántico que constituye una idealizada encarnación del honor y la fe españoles. Y es que, como certeramente escribe Joaquín Álvarez Barrientos, «Durante el siglo XVIII y el XIX se había ido trazando el camino que llevaba a esa exaltación de Calderón como enseña de la Patria» ${ }^{1}$ que culminaría con la celebración del segundo centenario de su muerte en 1881. Por supuesto, no fue Calderón el único escritor del Siglo de Oro que protagonizó aventuras de ficción en la época romántica: las peripecias biográficas de Cervantes, Quevedo, Lope de Vega y muchos otros autores áureos sirvieron de inspiración para los escritores románticos, tanto en el subgé-

${ }^{1}$ Álvarez Barrientos, 2002a, p. 7. Para la recepción de Calderón en el siglo xIx, ver la monografia de Manrique Gómez, 2011; y también Romero Tobar, 1981, Álvarez Barrientos, 2002a, y Oleza, 2003. 
nero de la novela histórica como en el del drama romántico². Escosura, que ya había dado entrada a Calderón como personaje secundario en La corte del Buen Retiro - pieza centrada en los supuestos amores de la reina Isabel de Borbón con el conde de Villamediana- y en su segunda parte, También los muertos se vengan (1844), lo convierte en protagonista en su drama de 1866-1867. Por otra parte, conviene recordar que tampoco fue Escosura el único en sacar a las tablas a Calderón como personaje dramático: Gil de Zárate lo introdujo en Un monarca y su privado $(1841)^{3} \mathrm{y}$, unas décadas después, en 1870 Emilio de Alcaraz compondría un drama en tres actos $y$ en verso original titulado Calderón ${ }^{4}$. A su vez, el folletinista Manuel Fernández y González lo convertiría en personaje de novela en El encanto de las musas, don Pedro Calderón de la Barca (1881-1882).

\section{Escosura y CALDERón}

Como sucede con muchos otros autores de la época romántica, la figura de Patricio de la Escosura ${ }^{5}$ (Oviedo, 1807-Madrid, 1878) presenta facetas muy variadas: fue militar, tuvo una destacada actividad política y

${ }^{2}$ Como escribe Ana Isabel Ballesteros Dorado, «A lo largo del siglo XIX se escribieron y representaron obras diversas sobre los autores más renombrados de los Siglos de Oro. Recuérdense, por ejemplo, las obras de Luis Eguílaz Alarcón (1853), Una aventura de Tirso (1855), Lope de Rueda (1870); o bien Garcilaso de la Vega (1840) de Gregorio Romero Larrañaga, así como El fénix de los ingenios (1853) de Tomás Rodríguez Rubí, Don Lope de Vega Carpio de Manuel García Muñoz o El nacimiento de Tirso (1879) de Francisco Flores García. También quedó retratado Cervantes en diversas piezas: Cervantes (1863) de Joaquín Tomeo y Benedicto o Los dos camaradas de Ventura de la Vega. Ninguna de las aludidas, sin embargo, alcanzó un éxito tan rotundo que supusiera permanecer como pieza de repertorio en los teatros. Sólo Don Francisco de Quevedo (1848), de Eulogio Florentino Sanz, logró tal distinción durante más de cincuenta años» (s. p.).

${ }^{3}$ Para la presencia de Calderón en Un monarca y su privado, de Gil y Zárate (1841), ver Montero Reguera, 1998. Al final de la Apoteosis de don Pedro Calderón de la Barca (1840) de José Zorrilla se ve «en un pedestal, decorado con insignias de triunfo, la sombra de don Pedro Calderón de la Barca, de cuerpo entero, coronada de laurel y mostrando la cruz de Santiago».

${ }^{4}$ Ver el trabajo de Ballesteros Dorado «Calderón pintado por Patricio de la Escosura y por Emilio Alcaraz en el siglo XIX».

${ }^{5}$ Para la vida y obra del autor ver especialmente Iniesta, 1958 (pp. 49-75 dedicadas a su teatro); Cano Malagón, 1989 (pp. 145-183 dedicadas a su teatro). Para su poesía, Paglia, 1994. Para las opiniones de Escosura sobre el teatro de Calderón, Iniesta, 1958, pp. 56-57 y Cano Malagón, 1989, p. 151. 
diplomática y fue, además de escritor y crítico literario, un activo periodista. Esta es la semblanza que nos ofrece Antonio Iniesta:

Una vida muy interesante: Conspirador en su juventud, militar, diputado, dos veces ministro y embajador, numerosas veces emigrado, siempre literato. Su biografia es característica de los hombres del siglo pasado. Como político, liberal en su pensamiento, siempre monárquico, se adhiere a numerosos partidos, sin hacer caso de su ideología, de la que desconfiaba.

Como literato, más que por su obra mediocre, interesa por haber ensayado las diferentes tendencias que aparecieron en su época, por lo que son de gran valor los juicios que nos ofrece de cada una de ellas, las dificultades que suponen para el escritor, su aceptación por parte del público, principalmente en un género que ha de estar muy cerca del público, como es el Teatro ${ }^{6}$.

Escosura se sumó a la moda de la novela histórica - a la manera de Walter Scott- y folletinesca — en la estela de Eugène Sue - con obras como El conde de Candespina (1832), Ni rey ni Roque (1835), El patriarca del Valle (1846) o La conjuración de México o Los hijos de Hernán Cortés (1850), entre otras, títulos a los que cabe sumar su célebre poema narrativo El bulto vestido del negro capuz (1835). Además, según nos recuerda Cano Malagón, fue «un fecundo y temprano cultivador» del drama histórico romántico que «se sintió siempre enamorado y defensor acérrimo de nuestro pasado histórico y literario»"

Su producción dramática está formada por títulos como La corte del Buen Retiro (1837), Bárbara Blomberg (1837), La aurora de Colón (1838), Don Jaime el Conquistador (1838), Higuamota (1839), Segunda parte de La corte del Buen Retiro o También los muertos se vengan (1844), Las mocedades de Hernán Cortés (1845), El amante universal (1847), Las flores de don Juan o Rico y pobre trocados (1849), Las apariencias (1850), ¿Cuál es mayor perfección? (1862), La comedianta de antaño (1867), Don Pedro Calderón (1867), Roger de Flor o los españoles en Oriente (1877) y Las noches lúgubres. Drama histórico del siglo XVIII (inédito), a los que podemos añadir las traducciones Cada cosa en su tiempo (1842), El tío Marcelo (1846) o El sueño de una noche de verano (1852).

\footnotetext{
${ }^{6}$ Iniesta, 1958, pp. 5-6.

${ }^{7}$ Ver Cano Malagón, 1989, pp. 147-148.
} 
Según Iniesta, Calderón «Es el autor favorito de Escosura. Para él, había llegado a mayor altura que los demás. Poseyó unas dotes muy superiores a ninguno otro por su intención y su genio poético» ${ }^{8}$. Si cedemos la palabra al propio Escosura, vemos que según él a Calderón

le encontramos siempre delante de su siglo, con pensamientos de una profundidad, de una trascendencia, que las más veces parecen proféticos; con un corazón de fuego, pintando pasiones volcánicas, crímenes gigantescos...; manejando en las comedias de capa y espada las pasiones de la sociedad con mano maestra, prestándole siempre la nobleza de su carácter; haciendo el amor más metafísico que nadie lo intentó nunca; complicando, en fin, sus intrigas hasta lo infinito?.

Escosura ya había llevado al teatro a Calderón —aunque no con papel protagónico - en las dos partes de La corte del Buen Retiro (1837 y 1844). Y en 1862 había compuesto ¿Cuál es mayor perfección? Auto dramático alegórico escrito a imitación de los sacramentales de don Pedro Calderón de la Barca, para servir de loa a la refundición de la comedia del mismo titulada "Mañanas de abril y mayo", y con ella representada en el teatro del Príncipe, la noche del 17 de enero de 1862, en celebridad del aniversario del natalicio de aquel gran poeta y príncipe de la escena española (1862). Tenemos que recordar, además, que Escosura firmaba su estudio introductorio del Teatro escogido de Calderón («Ensayo crítico sobre la vida y teatro de don Pedro Calderón de la Barca») el 30 de septiembre de 1866, y que esos volúmenes saldrían publicados en 1868. Si atendemos a estas fechas, y recordamos la del estreno de su comedia, 1867, podemos concluir que Escosura aprovechó sus investigaciones histórico-literarias sobre el autor de La vida es sueño para aproximarse a su figura también desde el plano de la ficción, componiendo una comedia en la que se pueden apreciar — además de características netamente románticas - otras que son claros ecos de la dramaturgia aurisecular.

${ }^{8}$ Iniesta, 1958, p. 56.

${ }^{9}$ Escosura, «Sobre el antiguo drama nacional», 1843; cito por Iniesta, 1958, p. 56.Y añade que fue "fidelísimo espejo de las costumbres, ideas y sentimientos de su época» (cito por Iniesta, 1958, p. 57). 


\section{Un argumento: Calderón Decide TOMAR LA ESPOSA MEJOR}

Don Pedro Calderón. Comedia en tres jornadas se estrenó el 25 de mayo de 1867, con motivo del aniversario de la muerte del dramaturgo ${ }^{10}$. El personaje de Calderón lo representó Victorino Tamayo, y las actrices principales fueron Teodora Lamadrid y Carmen Genovés. La acción pasa en Madrid en 1651, y la comedia de Escosura responde, en última instancia — y desde el plano de la ficción dramática-, a la pregunta de por qué Calderón decide tomar el estado eclesiástico en ese año. Como escribe Ángela Mañueco Ruiz,

Lo que más llama la atención es el final de la comedia con la abrupta elección del sacerdocio por parte de Calderón, que deja atónitos a personajes y espectadores. A pesar de ser un hecho real, en la obra resulta una solución muy forzada. De haberla inventado Escosura, se la habría rechazado por floja e inconsistente. Pero nuestro autor ha leído y meditado sobre Calderón y al buscar episodios de su vida infinitamente menos brillante y novelesca que la de Lope, quizás haya percibido en esta acción cierto misterio que puede utilizar, aunque con riesgo ${ }^{11}$.

La obra evocará la juventud aventurera, casi de burlador, de don Pedro en sus años mozos, pero nos lo presenta cuando ya está viejo (tiene cincuenta y un años), tras treinta de servicio al rey como soldado por toda Europa. En lo que sigue, no me detendré a comentar las inexactitudes o datos erróneos que presenta la pieza: no olvidemos que nos encontramos ante una obra literaria de ficción, no ante el trabajo objetivo de un historiador o biógrafo, al que sí cabe pedir rigor y exactitud en todas las informaciones que maneja ${ }^{12}$. Lo que en realidad importa, para mi propósito, es mostrar qué imagen de Calderón refleja la comedia, y esa es la de un dramaturgo-poeta que antes ha sido soldado, que no medra en la corte porque no es político (léase 'cortesano intrigante,

${ }^{10}$ Ballesteros Dorado, «Calderón pintado por Patricio de la Escosura y por Emilio Alcaraz en el siglo XIX», recoge algunas reseñas del estreno. En su análisis, destaca tres aspectos del retrato calderoniano en las piezas de Escosura y Alcaraz: la imagen del sabio que se retira del mundo, el honor y la lealtad monárquica. La obra de Escosura ha sido estudiada también por Álvarez Barrientos, 2000a.

${ }^{11}$ Mañueco Ruiz, 2004, pp. 369-370. Escosura reflexiona en su estudio biográfico sobre las razones de Calderón para ingresar al sacerdocio (Ensayo crítico sobre la vida y teatro de don Pedro Calderón de la Barca, pp. XLIII-XLVI).

${ }^{12}$ Para una reciente y completa biografia de Calderón ver Cruickshank, 2011. 
pretendiente': Calderón desea que se le reconozcan los méritos que por justicia le corresponden, pero no quiere rebajarse a tener que alegarlos él mismo escribiendo memoriales al rey o intrigando en los pasillos de palacio). Así pues, Escosura nos muestra un Calderón que vive pobre y solo, que es infeliz porque pesa sobre él un hado adverso (más adelante volveré sobre este detalle: exagerando un poco, la pieza podría haberse titulado Don Pedro o la fuerza del sino...); y un Calderón, y esto va a ser lo fundamental, que tiene una profunda fe en Dios y que en ese elemento de la religión va a encontrar la salida para todos los problemas de su existencia.

¿Y cuáles son esos conflictos que pesan sobre el dramaturgo? Ocurre que, en su mocedad, Calderón había estado enamorado de una dama de noble familia, doña Leonor Pimentel; la dama correspondía a esos amores, pero su familia dispone que se case con un pretendiente más poderoso, el conde de Guadarrama. En una pendencia callejera (cuando Calderón rondaba a la dama), el futuro escritor dejó herido a un familiar del conde y tuvo que refugiarse primero en sagrado y más tarde escapar a Milán. Con el tiempo, llegó a olvidar su amor por doña Leonor y ella, a su vez, sola y sin ayuda, se vio obligada a aceptar el matrimonio que le imponía su familia. Esta es la pre-historia de la acción, la cual se recupera informativamente para el espectador (o lector) en las escenas iniciales del drama.

En el momento presente de la acción, veinte años después — aproximadamente - de aquellos sucedidos, doña Leonor, que es viuda y es poderosa (en tanto sobrina del conde de Haro, valido del rey), pretende recuperar al que fue su antiguo amor de juventud, don Pedro, al que sigue amando incombustiblemente. Lo que pasa ahora es que Calderón ya no está enamorado de ella, sino de una joven prima de la condesa, doña Isabel de Mendoza, de veinte años, descrita de forma tópicamente romántica como un ángel de belleza y bondad, un serafín que enamora a todos cuantos la ven. Curiosamente, con Isabel se va a reproducir la situación vivida veinte años atrás por doña Leonor: tiene muchos pretendientes que la asedian y la familia la presiona para que se case; pero ella no quiere aceptar ningún marido impuesto, quiere ser libre y, en todo caso, solo aceptaría casarse con un hombre como Calderón. La condesa, celosa, tratará de acelerar la boda de Isabel con don César de la Cerda, su principal pretendiente. Lejos de empatizar con la joven (ella en su juventud vivió esa misma situación), la presiona a través de Haro 
para que case cuanto antes, eliminándola así como rival en sus amores por Calderón.

Añadamos ahora otro factor a la intriga dramática: Moreto. Sucede que el dramaturgo Agustín de Moreto también está enamorado de la condesa Leonor, solo que es apocado y no se atreve a declarar su sentimiento. Lo que hace es acudir a su íntimo amigo Calderón para que interceda en su favor y le ayude a averiguar si doña Leonor podría sentir algo por él. Esta petición de ayuda va a poner en un serio compromiso a Calderón y, de hecho, más adelante, cuando Moreto descubra a su amigo en conversaciones con su antiguo amor, interpretará que le ha traicionado.

En definitiva, con el discurrir de la acción Calderón se verá abocado a reñir dos duelos: con Moreto, que lo desafía por doña Leonor; y con don César de la Cerda, que lo desafia por doña Isabel. Además, va a existir la presión del rey para que estos conflictos se resuelvan. Calderón promete satisfacer a todos, aunque no sabe cómo hacerlo para: 1) obedecer al rey, quien le ordena que no acuda a los desafios y que se case cuanto antes (Leonor ha conseguido con su tío el de Haro que el monarca se implique en el asunto);2) aclarar las cosas con su amigo Moreto, que se siente traicionado (aunque nosotros, espectadores, sabemos que todo es un equívoco); 3) y lo mismo con don César, su rival en el amor por la joven Isabel. ¿Cuál es la única solución que se le ofrece a Calderón para salir de la encrucijada en que se encuentra? Casarse, sí, pero tomando la mejor esposa: la santa Iglesia católica, es decir, hacerse sacerdote. No nos extrañará, por tanto, que el título original de la obra, tal como fue presentado a la censura, fuese Tomar la esposa mejor.

Esta sorprendente solución a la que se llega en el desenlace se había ido preparando — acertadamente, a mi juicio — por medio de las diversas reflexiones de Calderón que ponen de relieve su desengaño del mundo, la idea reiterada una y otra vez a lo largo de la obra de que se siente viejo y cansado, hasta llegar a esa decisión de echarse en brazos de Dios para hallar la solución a todos los problemas: es decir, en los momentos de duda y zozobra, abandonarse a la fe y la esperanza. En este sentido, son muy significativos los cierres de las dos primeras jornadas:

1) Al final de la primera, Calderón entra en cólera al enterarse de que quieren casar a la joven e inocente doña Isabel. Ese amor callado 
que sentía por ella se enciende ahora como un fuego volcánico ( En mi pecho / arde un volcán», p. 39) y está dispuesto a desenvainar la espada para correr a matar a don César, el pretendiente de la joven. Sin embargo, el criado Clarín le recuerda a su madre fallecida, que le mira desde el cielo, y entonces Calderón se calma, deja la espada y agradece el consejo. Y el criado subraya: «iPues ya se encomienda a Dios, / en buenas manos le dejo!» (p. 41). Así, con Calderón rezando y encomendándose al cielo, acaba el primer acto.

2)Y algo muy similar sucede al final de la segunda jornada: Calderón, irritado por todos los contratiempos y celoso, se revela ante las dificultades que está viviendo, pero inmediatamente medita y se reporta, reconduciendo de nuevo la situación con un pensamiento piadoso: «iSeñor, mientras yo cumpla como bueno, / sé que en Vos hallaré misericordia!» (p. 94).

Estructuralmente, estos dos cierres de las dos primeras jornadas (cólera y rebeldía / fe y resignación) anticipan el desenlace, poniendo ya el énfasis en el elemento de la fe religiosa, que va a ser a la postre el que aporte la resolución definitiva del conflicto. Incluso es posible mencionar un par de pasajes (pp. 93-94 y 126) en los que se da una asimilación de Calderón con Cristo apurando el amargo cáliz de la Pasión. La alusión más claramente cristológica es la segunda. Calderón, cuya alma está sufriendo grandes tormentos, exclama:

¡Señor! Este amargo cáliz

si vuestro rigor ordena

que yo apure, ¡haced al menos

que no me falten las fuerzas! (p. 126).

Por otra parte, Calderón va a aparecer en varios momentos aludiendo a su deseo de apartarse del mundo:

... mas del amor y aun del mundo

me va veloz apartando

del tiempo implacable el curso (p. 17) ${ }^{13}$.

${ }^{13}$ Ver también las pp. 24, 32 y 124. 
3. La imagen de Calderón: «Cortesano sin favor / y pobre, AUnQue CABALLERO»

Ya he mencionado que «La acción pasa en Madrid: año 1651». Sucede, indica la acotación inicial de la Jornada primera, en casa de don Pedro Calderón: «Sala pequeña y modestamente amueblada, en la casa de don Pedro Calderón.- Reclinatorio con crucifijo.- Estante con libros.- Mesa grande con recado de escribir, cargada de libros y papeles.- Armas en las paredes». Esta didascalia reviste interés porque nos adelanta visualmente un par de informaciones que se verán corroboradas luego por los diálogos y la acción: nos habla de un Calderón que ha sido soldado, que ahora se dedica a la escritura dramática y vive pobre; y que tiene fe, y esa fe - como ya he señalado- va a ser el elemento decisivo en el desenlace de la pieza ${ }^{14}$.

En la escena I el criado Clarín, a solas, se queja de la desgracia de don Pedro, que antes fue soldado y ahora es poeta. En su opinión, en lugar de comedias debería escribir más memoriales (se entiende que al rey, para pedir el justo pago a sus años de servicio a la corona). Esta es, pues, la primera información que se nos ofrece sobre el protagonista:

Y a bien que servís a un amo, seor Clarín, de tal provecho, que parece que se ha hecho de las desdichas reclamo. Un menguado, ¡pesia a tal!, que, por soldado y poeta, su barca y la vuestra fleta viento en popa al hospital. Escriba, si ha de escribir, memoriales, no comedias; y de sus propias tragedias lástimas haga al pedir. Que es locura, jvive Dios!, hacer que llore el monarca

\footnotetext{
${ }^{14}$ Escribe Mañueco Ruiz, 2004, pp. 370-371: «Calderón es un autor de éxito, pero en lo cotidiano lo abruman las estrecheces económicas, la amargura de no haber sido suficientemente reconocido por sus méritos, el peso de los años, el temor al ridículo ante un tardío amor. Sólo lo mantiene erguido la imagen de valor que tiene de sí mismo, el honor. Por eso no puede aceptar a Isabel y romper una promesa, porque este hecho lo deshonraría ante sus propios ojos, los más rigurosos. Amargado busca la paz y la libertad personal que ha ido dejando en el camino de la vida».
} 
las desdichas del Tetrarca, y no las que pasáis vos (p. 2) $)^{15}$.

La escena II es clave para completar la información sobre el dramaturgo, tanto en lo que se refiere al momento actual como a su pasada juventud borrascosa. Llega a la casa doña Leonor con la dueña doña Lucía, ambas tapadas con mantos; la dama lleva además cubierto el rostro con media careta veneciana (p. 2, acot.). El diálogo entre doña Leonor y Clarín deja claro que Calderón fue poco menos que un burlador en sus años mozos, aficionado a lances de amor y aventureras pendencias de capa y espada. Ella y Calderón se amaban, pero el padre la quiso casar con el conde de Guadarrama; en una disputa Calderón dejó herido a un pariente del conde y tuvo que acogerse a sagrado para huir después a Milán. Doña Leonor, vencida su inicial resistencia, hubo de casarse con el marido impuesto. Ahora, muchos años después, es viuda y poderosa, y viene en busca de Calderón, del que sabe que no se ha casado. Este es el retrato del poeta en boca de su antigua enamorada:

\author{
Habrá... no sé cuántos años, \\ y poco a mi cuento importa, \\ que don Pedro Calderón \\ de la Barca, a quien abonan \\ de noble sus apellidos, \\ de claro ingenio sus obras, \\ mozo aún, mas ya poeta, \\ galán, valiente y de gloria \\ sediento, antes que de Marte \\ los laureles que hoy le adornan \\ conquistara, ceñir quiso \\ a su sien verde corona \\ del mirto de Venus... \\ [...] \\ Digo, Clarín, que don Pedro \\ a usanza de gente moza, \\ frecuentando Prado y Parque, \\ donde van las damas todas \\ de Madrid, como a palenque
}

\footnotetext{
${ }^{15}$ Todas las citas de la comedia son por la edición facsímil del año 2000, con algunos retoques en las grafias y la puntuación.
} 


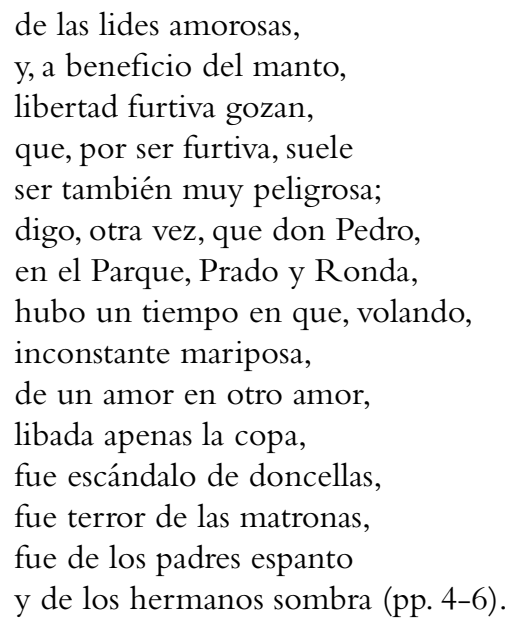

Esa fama del burlador —ella niña y hermosa, él galán y con ingenio- la atrajo sobremanera. Sin embargo, el criado del dramaturgo no quiere recordar tales aventuras y pondera más bien la nobleza de su amo:

Don Pedro es cátedra viva

de la ciencia de la honra;

y ha treinta años que la curso

corriendo con él la Europa (p. 8).

Doña Leonor, que se considera «su viuda», reconoce que, en efecto, «su trato / ennoblece y acrisola», y nos brinda la información de que Calderón no ha medrado, como sí hacen otros con muchos menos méritos que él:

Calderón nunca ha medrado;

y si en alas se remonta

de su ingenio a la alta cumbre

del Parnaso, si pregonan

del vate ilustre los triunfos

de la fama las cien trompas,

ni sus hazañas en Flandes,

en Milán y en Barcelona,

ni su nobleza y servicios

en la corte, ni sus obras,

lograron jamás favores

que a los hábiles se otorgan (p. 13). 
Más adelante (escena IV) vemos a Calderón departir con su amigo don Agustín Moreto, quien le pide que sea tercero en una relación amorosa: ama a la condesa de Guadarrama y quiere que su amigo averigüe si ella le corresponde. Calderón, en los apartes, se muestra preocupado por esta situación embarazosa. Se completa aquí la información de la escena II sobre doña Leonor.Y hallamos la primera mención al deseo del dramaturgo de apartarse del mundo. Calderón, que tiene ya «años de sesudo» (p. 17), se siente viejo y cansado. Toda la escena $V$ es un diálogo entre Calderón y Moreto; aunque se centra en el problema amoroso de este, se aporta información adicional sobre el protagonista principal: es «ejemplar / de caballeros» (p. 17); muchas veces su persona ha sido mordida por la envidia; y el único beneficio de tantos años de servicios en la guerra ha sido el hábito que lleva. Igualmente, este parlamento refuerza la idea del ideal monárquico-católico de Calderón, quien sirve lealmente al rey — aunque podría estar quejoso de él一 y tiene una acrisolada fe. Dice así:

$$
\begin{aligned}
& \text { Débil soy como mortal; } \\
& \text { y os confieso que mi orgullo, } \\
& \text { resentido, alguna vez } \\
& \text { iras y desmayos tuvo. } \\
& \text { Las iras templó el respeto } \\
& \text { que al rey profeso profundo; } \\
& \text { y en los desmayos, consuelo } \\
& \text { hallé en el Dios trino y uno } \\
& \text { que adoro, y en cuya fe } \\
& \text { vivir y morir procuro (p. 19). }
\end{aligned}
$$

Cuando Moreto le comenta que su ingenio no envejece, su amigo apostilla:

$$
\begin{aligned}
& \text { Pero sí el cuerpo caduco. } \\
& \text { Las canas de mi cabello, } \\
& \text { y de mi frente los surcos, } \\
& \text { las huellas son indelebles } \\
& \text { de los años en su curso (p. 24). }
\end{aligned}
$$

Un momento introspectivo de Calderón lo encontramos en el soneto de la escena VI. Como en las comedias del Siglo de Oro, podemos apreciar aquí el uso de la polimetría: las formas estándar con las que se 
va construyendo la pieza de Escosura son el romance, las quintillas y las redondillas, pero se reservan los versos endecasílabos para momentos de especial intensidad dramática o, como en este caso, de introspección del personaje ${ }^{16}$. Además, se introduce en este punto el tema del hado (la estrella contraria), que alcanzará cierto desarrollo:

¿Cuándo te has de cansar, estrella mía, más que cruel, en todo inoportuna, de tenerme en suspenso la fortuna, y con mi propio ser en lucha impía?

¿No te bastó robarme a la que un día amé, como jamás a otra ninguna ${ }^{17}$, y hoy en mi daño tu rigor aduna celos de amor, deberes de hidalguía?

Celos póstumos son... ¡Pero son celos! ¿Qué importa?... Mi palabra está empeñada; cumplirla es deuda, pese a mis desvelos,

que no hay pasión en mí que no sea honrada. ¡No sé si esto es pasión o si es memoria, mas al honor prometo la victoria! (p. 28).

Un nuevo diálogo entre el criado Clarín y Calderón insiste en la idea de la pobreza y soledad del dramaturgo, al que únicamente le queda la casa familiar como menguado resto de su patrimonio: «Solo estás y no muy rico...» (p. 31). Clarín resume la situación en que se encuentra actualmente el dramaturgo, y ello por no ser político (entiéndase 'cortesano'):

\author{
Yo tu mal te explicaré: \\ Ya estás en el punto crítico \\ de la vida.- ¿Eres político \\ o soldado?- No lo sé. \\ Hacer comedias, en ti \\ soberana habilidad, \\ no basta a tu calidad,
}

${ }^{16}$ Detalle ya notado por Iniesta: «rara vez aparecen, sólo en momentos de gran solemnidad, los metros de arte mayor, siguiendo el gusto de la época, que proscribía, en el diálogo especialmente, las estrofas de arte mayor» (1958, p. 72).

${ }^{17}$ En la edición de 1867 «niuguna», con la segunda $n$ vuelta del revés. 


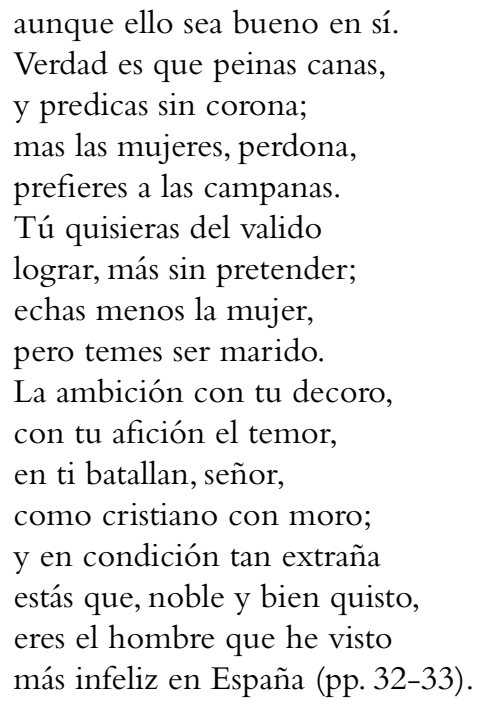

En la última escena de la primera jornada, Inés, criada de doña Isabel de Mendoza, trae un billete suyo para don Pedro: la prima de la condesa es un serafin de veinte años, a la que quieren casar a la fuerza. Apreciamos un tono quijotesco en la carta: ella pide ayuda a Calderón como si fuera un paladín que ha de acudir en socorro de una doncella acuitada y desvalida. Doña Isabel lo cita una hora antes de la academia de poetas que va a celebrarse esa noche. Calderón siente ahora celos al saber que don César de la Cerda pretende a esta niña y, en un arrebato de furia, se muestra dispuesto a la venganza. Pero inmediatamente se reporta, como subraya el comentario del criado Clarín: «iPues ya se encomienda a Dios, / en buenas manos le dejo!» (p. 41). Así pues, un Calderón pobre y solo, envuelto en enredos de amor, honor y amistad, es el balance que arroja esta primera jornada de la pieza de Escosura, escrita con buen lenguaje, aunque no exenta de algunos ripios ${ }^{18}$.

La Jornada segunda - que va a desarrollarse en casa de doña Leonor- explorará esos celos que ha empezado a sentir Calderón. Interesa destacar, a este efecto, el breve soliloquio de Calderón - una octava real- de la escena IV:

${ }^{18}$ Véase, por ejemplo, la rima Padrenuestro / estro (p. 53), o estos otros versos de doña Inés extractados de un pasaje de romance con rima $e$ : «¿Por qué buscar casamiento / con prisa y afán tan grandes, / cual si hubiera gatuperio, / o fuese fea la novia / y su padre algún hebreo?» (p. 37). 
Ya estáis conmigo, fieros en campaña, locos amores y tiranos celos; ¡cebad en mí el furor de vuestra saña, pues que así plugo a los divinos cielos! Mas el infierno que os mandó se engaña: no tiene llamas él, ni el polo hielos, que la deshonra impriman en mi frente ni entibien de mi fe la llama ardiente (p. 46).

En lo que respecta al retrato del dramaturgo, cabe mencionar también el diálogo pseudoamoroso que se establece entre la joven Isabel y Calderón (escena V), en el que ninguno de los dos puede decir con claridad lo que verdaderamente siente. Ella quiere libertad, no casarse con ninguno de los dos pretendientes que le han buscado. Las siguientes escenas van a mostrar la academia literaria organizada en casa de la condesa, en la que el tratamiento de los temas literarios se anuda con los sentimientos de los personajes. Así, Moreto sentirá el desdén de doña Leonor, que no le dedica ni una mirada; y la dama quedará celosa al saber que Calderón ha departido con doña Isabel. El diálogo que mantiene con su tío el conde de Haro pone de relieve la prisa con que quiere casar a su joven prima: contraerá matrimonio con don César o tendrá que ingresar en un convento. Calderón - de acuerdo con las maquinaciones de la condesa- podría ser nombrado gobernador, pero solo si casa con una dama noble. Le explica Haro:

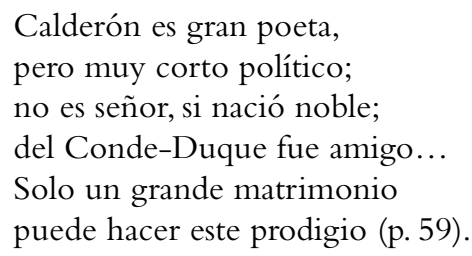

El final de la segunda jornada (escenas X-XVI) trae una serie de equívocos que van a complicar el enredo de la acción. Comienza con un chiste verbal, la dilogía de grande (pp. 63-64): cuando doña Leonor explica a Clarín que ella se quiere casar con Calderón y, de esa manera, hacerle grande, el criado responde con un «Ya lo es» (p. 64). La undécima es toda ella una escena de equívocos: la condesa dice que Calderón no es tan viejo para casarse y medrar, de esa forma, por medio de un matrimonio. Pero el dramaturgo, orgulloso, no quiere hacerlo por ese 
medio. Él dice que un vate famoso en Madrid ama a doña Leonor: ella piensa que Calderón se está refiriendo a sí mismo, cuando en realidad alude a Moreto... Cuando este se presenta, la condesa le recrimina por ser un nuevo Ícaro atrevido. Además, doña Leonor sigue empeñada en casar a Isabel o meterla monja. Calderón logrará que la deje tranquila a cambio de jurar que no corteja ni cortejará a la joven. Esta cree ahora que Calderón quiere casar con doña Leonor. La condesa da a Moreto esperanzas remotas a sus pretensiones si su amigo renuncia a ella. Moreto se muestra enfadado por la supuesta doblez y traición de su amigo Calderón, etc., etc. El acto se remata con una escena XVII, con Calderón a solas, en la que este glosa todas las desgracias que se ciernen sobre él, en un pasaje de versos endecasílabos que subraya desde el punto de vista métrico la gravedad de la situación:

¡Cielos!, ¿hay más desdichas que enviarme?

No os basta ya que beba la ponzoña; queréis, para que dure mi martirio, que agote el cáliz, pero gota a gota. ¿Cuál es mi culpa aquí? ¿Yo no renuncio, por verla libre, a la que el alma adora? ¿No pierdo el galardón a mis servicios por no rendir el cuello a una ambiciosa? No sirvo, amigo fiel, a quien me paga con locos celos?... ¡Si tal premio logra la virtud en el mundo, más valiera nacer engendro de las furias todas!!... ¿Qué dices, Calderón? ¡Tú blasfemaste!... ¡Dios perdone el delirio a mi congoja! ¡Señor, mientras yo cumpla como bueno, sé que en Vos hallaré misericordia! (p. 94).

La Jornada tercera, que se desarrolla en el palacio del Buen Retiro, va a estar marcada por la intervención real en el conflicto. Clarín y Guevara, oficial de ujier de cámara, comentan la ausencia de Calderón tras recibir un pliego con una orden (más tarde sabremos que del propio rey). El dramaturgo tiene que hacer frente a un doble desafio, con don César y con Moreto. Doña Leonor permanece recluida en su casa por orden del rey. Doña Isabel parece inclinarse al estado religioso. Haro teme que Calderón ambicione su puesto de valido del rey. Solo el monarca ha podido tener todo bajo control y convocar a todos los impli- 
cados en el Salón Dorado. Cuando llega Calderón, el de Haro le dice que el rey le ordena que se case y no riña con sus dos rivales, porque la ley prohíbe los duelos; si no obedece, incurrirá en la ira regia. La escena $\mathrm{XI}$ nos trae un nuevo soliloquio de Calderón, quien se debate (otra vez en metro grave, unas octavas reales) entre el cumplimiento del honor (batirse en duelo como caballero) y la obediencia debida al rey para, al final, dejar puesta su esperanza en Dios:

¿Viose jamás en tan difícil trance desdichado mortal, en esta vida? ¿De perderos habréis en este lance, honra por tantos años mantenida? ¿Está cumplir a un tiempo a vuestro alcance con la obediencia al rey siempre debida y la sangrienta obligación del duelo, que el mundo adora, si maldice el cielo? De vuestra infamia o rebelión, alarde ante una dama haced, noble y hermosa; iy tomad, ya rebelde o ya cobarde, tomad, y al punto, Calderón, esposa; que si una amasteis presto y otra tarde, cualquiera que elijáis será dichosa, pues una mano la ofrecéis proscrita, o por cobarde y sin honor maldita!! Mas aunque a un tiempo con el rey cumpliera y con la ley del duelo, dura, impía, ¿por eso, acaso, más benigno fuera el torvo influjo de la estrella mía? ¡Oh Leonor! ¡Oh Isabel! ¡Nunca yo os viera, rémoras de mi bien y mi hidalguía! ¡No quiero ser de la que soy amado; de la que adoro me lo estorba el hado! ¿Y por qué no ha de ser? -Poder humano nunca a mudar bastó los corazones. Si ella, aunque indigno soy, me da su mano, ¿qué me importan suplicios ni baldones? ¡Ay, que te pierdes, pensamiento insano, y lazos al honor ciego dispones! ¡Calderón! ¡Calderón! ¿ No se te alcanza que solo en Dios estriba tu esperanza? (pp. 114-115). 
Después Calderón, en diálogo con doña Leonor, explica que ha jurado no tomar como esposa a doña Isabel y ha jurado también obedecer al rey, que le manda casar. Ella insiste en que será grande si contrae matrimonio con ella. Asistiremos todavía a un nuevo soliloquio de Calderón (escena XV), que se debate en «esta lucha mortal / entre amor y mi conciencia»:

\author{
¡Ay! Las heridas del alma \\ no se curan con grandezas. \\ ¡Ni sin amor hay ventura \\ en uniones tan estrechas! \\ ¿Cuándo acabará el tormento? (p. 122).
}

Sigue un dramático diálogo entre doña Isabel y Calderón, en el que la joven — que habla del dramaturgo en tercera persona - deja entrever que le ama y está dispuesta a casarse con él:

$$
\begin{aligned}
& \text {... todo Madrid confiesa } \\
& \text { que es, sin jactancia, valiente; } \\
& \text { dechado de la nobleza; } \\
& \text { buen cristiano, aunque galante, } \\
& \text { razonable, aunque poeta; } \\
& \text { de bronce para los fuertes, } \\
& \text { para los humildes cera; } \\
& \text { y no me parece mal, } \\
& \text { si bien sé que canas peina (p. 124). }
\end{aligned}
$$

Calderón también desvela su amor:

$$
\begin{aligned}
& \text { ¡Yo os adoro, mi Isabel, } \\
& \text { con ardiente pasión ciega! } \\
& \text { Yo os adoro, aunque locura } \\
& \text { en mis años tal vez sea, } \\
& \text { ¡que soy árbol tan sin savia } \\
& \text { como vos lozana yedra! (p. 125); }
\end{aligned}
$$

y se lamentará al verse sentenciado por el destino a perder honra o ventura... Desde la escena XVII, en que se encomienda a Dios, se prepara el desenlace providencialista: un Calderón iluminado tiene una idea, reza y escribe una carta al rey, que manda con Guevara. Cuando Haro le pida su respuesta al mandato del monarca, asegura el dramaturgo que su 
elección está hecha y que con ella dará satisfacción a todos. Doña Isabel y doña Leonor creen ser la elegida. Pero Calderón sorprende a los presentes diciendo que su esposa será la santa Iglesia católica ${ }^{19}$. Cuando el conde de Haro señala que ha triunfado de todos, él responde:
Antes a todos me rindo y de hoy más me humillaré.
Don César, don Agustín, ya un rival en mí no veis. Leonor, la que ya os prefiero no ofende vuestra altivez; $\mathrm{y}$ aun por ella es sacrificio renunciaros, Isabel, que si Dios lo toma en cuenta, ¡su piedad me ha de valer! Aquí del mundo renuncio pompas vanas, gloria y ley; aquí trueco armas profanas por las armas de la fe.
Mi musa será, de hoy más, la del vate de Israel, y pues la mejor esposa dado me ha sido escoger, su gracia hará que, cantor de honra y Patria y Dios y Rey, ni mi nombre muera nunca ni se agoste mi laurel (pp. 134-135).

Queda, tan solo, el ultílogo de Clarín pidiendo un aplauso para el poeta, «que culpa suya no fue / atreverse a su grandeza / tan poco diestro pincel»(p. 135).Y el Epílogo $o^{20}$, en el que Lope de Vega abre a Calderón las puertas del templo de la Fama, vaticinando que será eterno.

${ }^{19}$ No se alude al destino posterior de las damas y sus otros pretendientes, ni se conciertan parejas como en los finales tópicos de las comedias áureas.

${ }^{20}$ Copio la nota que lo acompaña: «Esta fantasía dramática, puramente de circunstancia, fue improvisada para su objeto, y lo fue, tanto como por el poeta, por los actores y por la empresa, que en veinte y cuatro horas hubieron de estudiarla, ensayarla y ponerla en escena. A los primeros, ya el público les hizo justicia con sus aplausos, y saben cuán agradecido les estoy; pero no está de más expresárselo aquí de nuevo, por toda la representación, ni sería justo callar que el inteligentísimo director de escena, D. Diego Luque, fue quien, con su habitual celo y con la felicidad que el público ha reconocido, 
Calderón, por su parte, reitera la idea de que ya no dará entrada a más asuntos profanos en su teatro.

\section{ECOS AURISECULARES Y «ROMANTICISMO AMBIENTE»: LA ESTRELLA CON- TRARIA DE CALDERÓN}

En la comedia de Escosura podemos apreciar claramente la huella de elementos procedentes del teatro - y la literatura, en general- del Siglo de Oro. Así, cabe afirmar que la estructura general de la comedia, con trama que combina amores, celos y enredos, rivalidades de amistad y poder, conflictos entre el honor y el deber, etc., etc., responde a patrones áureos bien conocidos por Escosura como lector y editor del teatro calderoniano. Destacaré además la presencia de mujeres tapadas en la primera jornada (doña Leonor y doña Lucía con mantos, p. 2 acot.; doña Inés con manto y tapada, p. 33 acot.). La Jornada segunda se abre con una escena tópica del teatro áureo, el enfrentamiento verbal entre un criado gracioso, Clarín, y una dueña vieja de tocas venerables, doña Lucía (pp. 44-45; ver también la alusión a la dueña colmilluda en la p. 29). La academia literaria de la segunda jornada tiene asimismo precedentes clásicos. No olvidemos la alusión metateatral del comienzo de la jornada tercera ( De tan misterioso lance / ni en palacio he visto ejemplo, / ni a inventarlo en sus comedias / alcanzó el mismo don Pedro", p. 95). Como un eco del teatro áureo podríamos considerar igualmente el empleo de la polimetría, reservándose los versos de arte mayor para destacar desde el punto de vista métrico aquellos momentos de especial emoción o intensidad dramática (por ejemplo, varios soliloquios de Calderón ${ }^{21}$. No me puedo detener en la figura del criado Clarín, que responde - ya desde su mismo nombre ${ }^{22}$ - al prototipo de criado gracioso, fiel sirviente de Calderón, urdidor de algunos enredos y portavoz

dispuso el cuadro final mucho mejor que hubiera podido nunca imaginarlo el autor del epílogo» (p. 137).

${ }^{21}$ Por supuesto, a lo largo de la obra se rastrean muchas alusiones que tienen que ver con la indumentaria y la moda, comidas y bebidas, tratamientos, costumbres y usos sociales de la España del Siglo de Oro. También ciertos tópicos literarios, como el de la dama amada considerada «dulce enemiga bella» (p. 76, Isabel para de la Cerda) o el soy quien soy (para connotar 'nobleza', p. 29).Y algunas alusiones a topónimos (Prado, San Blas, etc.) que sirven para reforzar la ambientación madrileña de la acción.

${ }^{22}$ Ver algunos chistes con el nombre de Clarín en la p. 35. 
de la comicidad escénica y verbal (ver algunos ejemplos en las pp. 4, 5, $7-8,10,17,38$, etc.).

Hay también alusión a algunas obras dramáticas del propio Calderón. Dejando de lado ciertas alusiones indirectas (a El mayor monstruo del mundo, cuando se habla de las desdichas del Tetrarca en la p. 2; a El alcalde de Zalamea, por la mención del maestre Figueroa en la p. 11; quizá a Basta callar en las pp. 54 y 107; a Amado y aborrecido, que es el texto que sirve de glosa para la academia poética en las pp. 77 y ss.; una referencia al ensayo que se hace de Manos blancas no ofenden, en la p. 98, etc.), hay que mencionar sobre todo dos ecos muy claros de los célebres versos de El alcalde de Zalamea "Al rey la hacienda y la vida / se ha de dar...». Primero, cuando doña Leonor quiere hacer grande a Calderón casándose con ella, él protestará alegando que su orgullo no se lo permite:

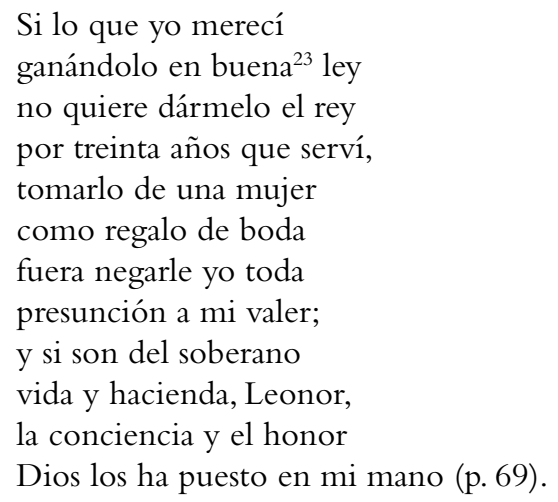

Hacia el final de la pieza se sabe que Calderón ha estado ausente por mandato del rey, y que él ha sido obediente aun a costa de su fama.Y él mismo comenta:
Mas, si no basta esa pena, la que guste el rey me imponga: todo es suyo cuanto tengo menos el alma y la honra (p. 113).

Desde el punto de vista estilístico, cabe señalar que abundan en la obra las referencias emblemáticas y de la tradición animalística: el ena-

${ }^{23}$ En la edición de 1867 «bueua», con la $n$ vuelta del revés. 
moradizo Calderón mozo es presentado como inconstante mariposa (p. 6); se mencionan el cedro altivo que resiste a los vientos (p. 9), el águila que puede mirar directamente al sol (p. 22), la palma del desierto que crece sola (p. 52), la tórtola amante, el girasol, la hiedra abrazada al tronco (pp. $52-53$, en un pasaje, por cierto, que adopta la estructura de una enumeración diseminativo-recolectiva, aunque sin la perfección formal de las calderonianas); el lince que tiene buena vista (p. 59), la víbora 'celos' (p. 60), la hiedra y el árbol (p. 125), etc., algunas de ellas en expresiones ya lexicalizadas: las «palaciegas / aguas turbias, procelosas» (p. 14); el mar de la vida (p. 18); las dos damas, la madura doña Leonor y la joven doña Isabel, son respectivamente el otoño y el abril (p. 105).

También encontramos diversas alusiones mitológicas o a personajes y elementos de la antigüedad clásica: Clarín como trompa de la fama (p. 6), Diana y Endimión (p. 22), Vesubio ‘cólera y celos' (p. 24), la condesa, que se conserva bella en su edad madura, es vencedora de Saturno (p. 26); la contraposición oro / honor (p. 27); los poetas como sacerdotes y ministros de Apolo (p. 55); Venus (p. 60), Júpiter y Mercurio (p. 62; el ujier Guevara es mercurio de la Corte, p. 118); dejar pasar la ocasión (pp. 67, 125), Fortuna es hembra (p. 68), alusiones indirectas al mito de Ícaro (pp. 74-75: Moreto, enamorado de la Condesa, es una especie de nuevo Villamediana que pretende volar demasiado alto y corre el riesgo de caer desde la altura a la que quiere encumbrarse); Apolo, ingenio de los poetas (p. 80), Dafne y Apolo (p. 81), dar la oliva 'ofrecer la paz' (p. 99), Cerbero (p. 96), las furias y Circe (p. 107), poner un clavo a la rueda de la fortuna (p. 122), etc. Notemos además la alusión a la maga Armida - personaje de la Gerusalemme liberata de Torquato Tasso-y sus encantamientos (pp. 57, 107).

Pero, más allá de estas referencias auriseculares y cultas, la obra de Escosura responde también, desde su concepción y estilo, al «romanticismo ambiente», triunfante en España en los años 30-40, pero todavía vigente en los 60 del siglo XIX. Que Don Pedro Calderón de Escosura es una obra romántica lo apreciamos claramente en el argumento, al presentarnos a este Calderón que es un héroe romántico sui generis: un cincuentón Amadís sobre el que pesa la fuerza de una estrella contraria. Véase especialmente el ya citado soneto de la Jornada I, escena VI, que comienza:

¿Cuándo te has de cansar, estrella mía, más que cruel, en todo inoportuna, 
de tenerme en suspenso la fortuna

y con mi propio ser en lucha impía? (p. 28).

Cuando doña Leonor le diga: «Nacisteis en signo torpe», él replicará «Y, sobre torpe, maligno» (p. 66). Si ella señala que, luchando, es posible enmendar la estrella (p. 66), añadirá él: «Medio siglo ha que es impía / y lucho en vano con ella» (p. 66); más adelante se quejará de «Ser mi suerte en todo adversa» (p. 75), en otro momento hablará de «el torvo influjo de la estrella mía» (p. 114) y comentará que el hado estorba el amor de la mujer que adora (p. 115); en otro pasaje exclamará: «Tal es mi suerte de fiera, / que la ventura o la honra / forzoso será que hoy pierda» (p. 125), para reiterar enseguida que «a perder honra o ventura / el destino me sentencia» (p. 125). Tal es, en efecto, la «estrella cruel» (p. 130) que pesa sobre Calderón.

Esas alusiones al hado, al sino contrario, también se aplicarán a otros personajes: doña Leonor explica que «del hado injusto / a entrambos hirió la cólera...» (p. 7), y doña Isabel alude igualmente a "aquel / que nace en sino cruel» (p. 84). Esta joven, por cierto, reúne igualmente en su persona características de heroína romántica, pues en todo momento se rebela contra el matrimonio que le quiere imponer su familia y defiende su libertad para amar a quien quiera (ver, por ejemplo, las pp. 49 y 51).

En fin, la condición romántica de la obra la notamos asimismo en algunos detalles como la adjetivación empleada en determinados pasajes, con empleo de epítetos tópicos: noches claras y lóbregas (p. 10), aciaga noche (p. 11), satánica soberbia (p. 120), etc.

\section{A MODO DE CONCLUSIÓN}

Don Pedro Calderón de Patricio de la Escosura es una comedia de amor, celos y enredo, honor y amistad, etc., con leves ribetes de drama de poder ${ }^{24}$, que nos presenta a un Calderón que se debate entre el amor y el deber, la obediencia al rey y a la ley del duelo. El protagonista es un Calderón viejo, solo, pobre e infeliz, pero al mismo tiempo galante y enamoradizo, valiente y piadoso. Honor, valentía, caballerosidad, obediencia y lealtad al rey, más una acrisolada fe religiosa, son los principales rasgos que conforman su personalidad en esta obra de ficción. El final

\footnotetext{
${ }^{24}$ En varios momentos se alude a la necesidad del secreto y el silencio en la corte, si bien este tema no alcanza un mayor desarrollo dramático.
} 
de las tres jornadas pone de relieve la inclinación religiosa del personaje. Obvio es decir que a lo largo de toda la comedia y, por supuesto, en el Epílogo añadido asistimos a la glorificación de Calderón, que queda convertido en la quintaesencia del caballero católico español.

Desde el punto de vista dramático-literario, cabe destacar las reminiscencias auriseculares. Más allá de la estructura general de la pieza (galanes, damas, rivalidades amorosas, enredos, celos, riñas y otros lances...), o las escenas tópicas de criados y viejas dueñas, etc., los ecos del Siglo de Oro se aprecian en el buen "color local», en la acertada recreación del ambiente por medio del léxico o la alusión a costumbres, modas y usos sociales. Escosura demuestra tener un buen conocimiento de la sociedad española del XVII. La obra destaca además por la abundancia de alusiones cultas, mitológicas y emblemáticas (sin llegar al extremo de la erudición, hay cierta densidad de motivos y tópicos literarios). En cuanto a la métrica, la versificación es ágil y fluida, algo habitual en las obras dramáticas de Escosura.

En fin, como sucede con muchas de estas piezas románticas - $\mathrm{O}$ posrománticas- que convierten en personajes de ficción, tanto en narrativa como en teatro, a los grandes escritores del Siglo de Oro (lo mismo sucede con Cervantes, Quevedo, Lope, etc.), la calidad literaria no es quizá demasiado elevada, pero resultan obras interesantes porque nos sitúan en la línea de interpretación y valoración de estos autores. En este caso concreto, la comedia de Escosura nos muestra cómo se concebía a Calderón en ese momento en que se estaba convirtiendo en mito nacional, en una encarnación simbólica del espíritu y los valores españoles. 


\section{BibLIOGRAFÍA}

Alcaraz, Emilio de, Calderón. Drama en tres actos y en verso original de..., Madrid, Manuel Pedro Delgado (Imp. de D. P. López), 1870.

Álvarez Barrientos, Joaquín, «Honra y patria, Dios y rey», estudio preliminar a Patricio de la Escosura, Don Pedro Calderón. Comedia en tres jornadas, escrita a imitación de las de nuestro teatro antiguo, ed. facsímil, Pamplona, GRISOUniversidad de Navarra, 2000a, pp. 7-37.

Álvarez Barrientos, Joaquín, «Pedro Calderón de la Barca en los siglos XviII y XIX: fragmentos para la historia de una apropiación», en Estado actual de los estudios calderonianos, coord. Luciano García Lorenzo, Kassel, Edition Reichenberger, 2000b, pp. 279-324.

Ballesteros Dorado, Ana Isabel, «Calderón pintado por Patricio de la Escosura y por Emilio Alcaraz en el siglo XIX», en Calderón de la Barca y su aportación a los valores de la cultura europea (Actas de las Jornadas Internacionales de Literatura Comparada celebradas en la Universidad San Pablo-CEU los días 14 y 15 de noviembre de 2000), disponible en: <http://cvc.cervantes.es/literatura/calderon_europa/ballesteros.htm > [12/06/2014].

Cano Malagón, María Luz, Patricio de la Escosura: vida y obra literaria,Valladolid, Secretariado de Publicaciones e Intercambio Editorial de la Universidad de Valladolid, 1989.

Calderón de la Barca, Pedro, Teatro escogido de D. Pedro Calderón de la Barca, ed. de la Real Academia Española, Madrid, Imprenta y Estereotipia de M. Rivadeneyra, 1868.

Cruickshank, Don William, Don Pedro Calderón: su carrera secular, trad. José Luis Gil Aristu, Madrid, Gredos, 2011.

Escosura, Patricio de la, «Sobre el antiguo drama nacional», El Reflejo (Madrid), núm. 10, 1843, pp. 78-79.

Escosura, Patricio de la, Don Pedro Calderón, comedia en tres jornadas, escrita a imitación de las de nuestro teatro antiguo, por don..., de la Real Academia Española. Representada por primera vez en el teatro de Jovellanos, el 25 de mayo de 1867, aniversario de la muerte del Príncipe de nuestros poetas dramáticos, con un Epílogo fantástico, improvisado al efecto, Madrid, El Teatro y Administración LíricoDramática [Imprenta de José Rodríguez], 1867.

Escosura, Patricio de la, Don Pedro Calderón. Comedia en tres jornadas, escrita a imitación de las de nuestro teatro antiguo, ed. facsímil de la de 1867 con estudio de Joaquín Álvarez Barrientos, Pamplona, GRISO-Universidad de Navarra, 2000.

Escosura, Patricio de la, «Calderón considerado como moralista dramático», Revista de España (Madrid),VI, 22, 1869, pp. 161-210.

Escosura, Patricio de la, Ensayo crítico sobre la vida y teatro de don Pedro Calderón de la Barca, en Teatro escogido de D. Pedro Calderón de la Barca, ed. de la Real 
Academia Española, Madrid, Imprenta de M. Rivadeneyra, 1868 (Biblioteca Selecta de autores clásicos españoles, VII), tomo I, pp. V-CLXII.

Escosura, Patricio de la, «El Demonio como figura dramática en el teatro de Calderón», Revista de España (Madrid), XLV, 1875, pp. 337-356 y 433-450. InIesta, Antonio, D. Patricio de la Escosura, Madrid, Fundación Universitaria Española [Talleres Gráficos «JURA»], 1958.

Manrique Gómez, Marta, La recepción de Calderón en el siglo XIX, Madrid / Frankfurt, Iberoamericana / Vervuert, 2011.

Mañueco Ruiz, Angela, "Calderón como personaje en el teatro romántico», en Actas del XIV Congreso de la Asociación Internacional de Hispanistas: New York, 16-21 de Julio de 2001, coord. Isaías Lerner, Roberto Nival y Alejandro Alonso, vol. 3 (Literatura española, siglos XVIII, XIX y XX), Newark (Delaware), Juan de la Cuesta, 2004, pp. 367-371.

Montero Reguera, José, "Calderón de la Barca sale a la escena romántica», en Estudios de literatura española de los siglos XIX y XX. Homenaje a Juan María Díez Taboada, coord. José Carlos de Torres Martínez y Cecilia García Antón, Madrid, CSIC, 1998, pp. 324-329.

Oleza, Joan, «Calderón y los liberales», en Giornate calderoniane. Calderón 2000. Atti del Convengo Internazionale, Palermo 14-17 Dicembre 2000, ed. Enrica Cancelliere, Palermo, Flaccovio Editore, 2003, pp. 395-418.

Paglia, Giuseppe, Retorica e passione nella poesia romántica di Patricio de la Escosura, Parma, Istituto di Lingue e Letterature Romanze de la Università degli Studi di Parma, 1994.

Romero ToBAr, Leonardo, "Calderón y la literatura española del siglo XIX», Letras de Deusto, 11, 22, 1981, pp. 101-124. 